\title{
Orally administered S-1 suppresses circulating endothelial cell counts in metastatic breast cancer patients.
}

\section{$\operatorname{AUTHOR(S):~}$}

Tsuji, Wakako; Ishiguro, Hiroshi; Tanaka, Sunao;

Takeuchi, Megumi; Ueno, Takayuki; Toi, Masakazu

\section{CITATION:}

Tsuji, Wakako ... [et al]. Orally administered S-1 suppresses circulating endothelial cell counts in metastatic breast cancer patients.. International journal of clinical oncology 2013

ISSUE DATE:

2013-06-06

URL:

http://hdl.handle.net/2433/180780

\section{RIGHT:}

The final publication is available at link.springer.com; 許諾条件により 本文は2015-06-06に公開.; この論文は出版社版でありません。引用の 際には出版社版をご確認ご利用ください。; This is not the published version. Please cite only the published version. 
Orally Administered S-1 Suppresses Circulating Endothelial Cell Counts in Metastatic Breast

\section{Cancer Patients}

Wakako Tsuji $^{1}$, Hiroshi Ishiguro ${ }^{2}$, Sunao Tanaka ${ }^{1}$, Megumi Takeuchi ${ }^{1}$, Takayuki Ueno ${ }^{1}$, Masakazu Toi $^{1}$

Authors' affiliations:

1. Division of Breast Surgery, Department of Surgery, Graduate School of Medicine, Kyoto University

2. Outpatient Oncology Unit, Kyoto University Hospital

Running title:

S-1 Suppresses Circulating Endothelial Cells

Corresponding author: Wakako Tsuji

Mailing address: 54 Kawara-cho Shogoin Sakyo-ku Kyoto, Japan

Tel: $81-75-751-3660$

Fax: $81-75-751-3616$

E-mail: w-sato@kuhp.kyoto-u.ac.jp 


\begin{abstract}
Background: S-1 is an oral cytotoxic preparation that contains tegafur. Gamma-butyrolactone (GBL) is a metabolite of tegafur that is known to suppress vascular endothelial growth factor (VEGF)-mediated angiogenic activity. The aim of this study was to determine the change in Circulating Endothelial Cells (CEC) counts, GBL levels, and angiogenesis-related factors during S-1 administration in metastatic breast cancer (MBC) patients.
\end{abstract}

Methods: Patients with HER2-negative MBC were eligible. S-1 was administered orally twice daily in a 4-week-on/2-week-off cycle until disease progression or unacceptable toxicity occurred. Blood was collected on the following days: day 1, day 43, day 85 (before each cycle of S-1 administration), day 15, day57 (1 h after S-1 administration), and day29. The CellSearch ${ }^{\circledR}$ system was used to count the CECs. Gas chromatographic-mass spectrometric method was used to measure plasma GBL and 5-FU levels. Levels of VEGF were assayed by enzyme-linked immunosorbent assay.

Results: A total of 18 patients were enrolled. The plasma GBL levels on day 15 and day 57 were $41.3 \pm$ $15.8 \mathrm{ng} / \mathrm{mL}$ and $41.0 \pm 11.2 \mathrm{ng} / \mathrm{mL}$, respectively. The CEC levels decreased on day 15 , and significantly low levels were maintained until day 85 ( $P=0.002$ vs. day 1$)$. The plasma VEGF levels significantly decreased on day 15 ( $P=0.012$ vs. day 1$)$ and had a tendency to decrease until day 57 .

Conclusions: This exploratory study showed that GBL levels increased, VEGF levels decreased, and CEC levels were suppressed during S-1 administration. S-1 appears to have anti-angiogenic activity. 


\section{Mini-abstract}

This exploratory study showed that GBL levels increased, VEGF levels decreased, and CEC levels were suppressed during S-1 administration. S-1 appears to have anti-angiogenic activity.

\section{Key words}

Circulating endothelial cells (CECs); Gamma-butyrolactone (GBL); antiangiogenic effect; metronomic chemotherapy; S-1 


\section{Introduction}

Metastatic breast cancer (MBC) is rarely curable, which increases the importance of maximizing the quality of life during treatment. Currently, mainstream chemotherapy for MBC is delivered at the maximum tolerable dose (MTD), usually given every few weeks. An alternative approach is metronomic chemotherapy, which is characterized by relatively low dosages and more frequent administration of the chemotherapeutic agent that typically results in fewer side effects and better quality of life ${ }^{1}$.

Two of the agents that meet the characteristics of metronomic chemotherapy are UFT and S-1. S-1 consists of tegafur (FT), 5-chloro-2,4-dihydroxypyridine and potassium oxonate at a molar ratio of 1:0.4:1, respectively. UFT, an oral fluoropyrimidine that combines FT and uracil at a molar ratio of 1:4, was developed earlier than S-1 ${ }^{2}$. The chief component of both S-1 and UFT is FT, which is a prodrug of 5-fluorouracil (5FU) ${ }^{3}$. Patients with positive hormone receptor status treated with UFT showed longer relapse-free survival than those treated with CMF in clinical trials ${ }^{4,5}$. The hormone receptor-positive and HER2-negative subpopulations of patients are not as responsive to treatment with anthracycline or taxane

${ }^{6,7}$. S-1 is also expected to be particularly effective in patients with positive hormone receptor status.

Metronomic chemotherapy is considered to inhibit tumor growth by anti-angiogenic effect via direct targeting of dividing endothelial cells in the growing tumor vasculature and of circulating endothelial progenitors (CEPs) ${ }^{8,9}$. MTD chemotherapy induced robust CEP mobilization and tumors 
rapidly became resistant ${ }^{1}$. Metronomic chemotherapy is sometimes effective at targeting tumors that are resistant to chemotherapy with MTD because the main targets of metronomic chemotherapy are the endothelial cells of the growing vasculature of the tumor ${ }^{9,10}$. Administration of metronomic cyclophosphamide (CPA) is reported to maintain low levels of viable circulating endothelial cells (CECs) for a long period of time by avoiding mobilization of CEPs ${ }^{1}$. FT is metabolized into 5FU, $\gamma$-butyrolactone (GBL), and $\gamma$-hydroxybutyric acid (GHB). GBL and GHB are tautomers under physiological conditions and are known to suppress tumor-mediated or VEGF-mediated angiogenic effects ${ }^{11,12}$. In a mouse model of MBC, low doses of CPA and UFT resulted in remarkable prolongation of survival and decline in viable CEPs without myelosuppression ${ }^{9}$.

To optimize metronomic chemotherapy, development of reliable surrogate markers for anti-angiogenesis may be useful. Several studies have reported that changes in CEPs could act as a biomarker for monitoring therapeutic effect ${ }^{1,13-17}$. The numbers of CEPs are higher in breast cancer patients with Stage III/IV than in patients with Stage I/II, and the numbers decline after chemotherapy ${ }^{16}$. The maximum reduction in CEPs is strongly correlated with the anti-angiogenic effect ${ }^{17}$. From these findings, the assumption arises that S-1 has anti-angiogenic effects that results in declining CEPs if S-1 is shown to have a similar anti-angiogenic effect as that of UFT ${ }^{12,18}$. CECs are increased in cancer patients compared with non-diseased individuals and have been suggested as potential predictors of clinical response ${ }^{1,14,15,19,20}$. The change in CEC counts differs for each chemotherapeutic agent. A CEC count 
greater than $11 / \mu \mathrm{L}$ after 2 months of metronomic chemotherapy with oral $2.5 \mathrm{mg}$ of methotrexate and 50

mg of CPA administration was associated with significantly prolonged overall survival in MBC patients ${ }^{20}$.

Metronomic methotrexate and CPA administration lets CEC counts increase, but the change in CEC count

for S-1 administration is unknown so far. The main purpose of this study was to explore corresponding

levels of CECs in MBC patients during S-1 administration. Another purpose was to assess the change in

GBL levels and angiogenesis-related factors: VEGF, monocyte chemo-attractant protein-1 (MCP-1), and thrombospondin-1 (TSP-1) ${ }^{21,22}$. Furthermore, the changes in the circulating tumor cells (CTCs), M30 and M65 were also determined.

\section{Patients and methods}

\section{Patients}

Patients aged 20 years and older with histologically confirmed invasive breast cancer and the following were eligible: MBC that was not necessarily measurable according to the Response Evaluation Criteria in Solid Tumors; Eastern Cooperative Oncology Group performance status of 0-2; negative HER2 status; adequate bone marrow and organ functions (WBCs $\geq 3000 / \mathrm{mm}^{3}$ or neutrocytes $\geq 1500 / \mathrm{mm}^{3}$, platelets $\geq 10 \times 10^{4} / \mathrm{mm}^{3}$, hemoglobin $9.0 \mathrm{~g} / \mathrm{dL}$, AST $\bullet$ ALT $\leq 2.5 \times$ the upper limit of normal range adopted by the institute, total bilirubin $\leq 1.5 \mathrm{mg} / \mathrm{dL}$, creatinine $\leq 1.2 \mathrm{mg} / \mathrm{dL}$, creatinine clearance $\geq 60 \mathrm{~mL} / \mathrm{min}$ ). Patients who had already received S-1 within the previous 12 months were excluded. Patients were also 
excluded if they had an active concomitant malignancy, a history of allergy to fluorinated pyrimidine, interstitial pneumonia, or pulmonary fibrosis. The use of fluorinated pyrimidine, steroids, or flucytosine was not allowed. Pregnant or lactating women were excluded. Written informed consent was required from all participants.

\section{Study design}

The patients received S-1 (Taiho Pharmaceutical Co., Ltd., Tokyo, Japan) orally for 28 consecutive days, followed by a 14-day rest period (Fig. 1a). Cycles were repeated every 42 days until disease progression or unacceptable toxicity occurred. The standard dose of S-1 was determined on the basis of body surface area (BSA) as follows: for BSA $<1.25 \mathrm{~m}^{2}, 80 \mathrm{mg} /$ body/day; for $1.25 \mathrm{~m}^{2} \leq$ BSA $<$ $1.5 \mathrm{~m}^{2}, 100 \mathrm{mg} /$ body/day; and for $1.5 \mathrm{~m}^{2} \leq \mathrm{BSA}, 120 \mathrm{mg} /$ body/day. The standard dose was given daily in two divided doses. One point of blood was collected on each of the following days: day 1 (before the $1^{\text {st }}$ cycle of S-1 administration), day 15 ( $1 \mathrm{~h}$ after S-1 administration), day 29 , day 43 (before the $2^{\text {nd }}$ cycle of S-1 administration), day 57 ( $1 \mathrm{~h}$ after S-1 administration), and day 85 (before the $3^{\text {rd }}$ cycle of S-1 administration). This explorative trial was approved by the Kyoto University Graduate School and Faculty of Medicine Ethics Committee and registered with the University Hospital Medical Information Network, number UMIN000002793. 


\section{Biomarker evaluations}

On days $1,15,29,43$, and $85,20-\mathrm{mL}$ aliquots of blood were collected into two CellSave Preservative Tubes (Veridex LLC, Co., Ltd, NJ, USA) containing a cell preservative. Blood samples for CECs and CTCs were kept at room temperature and centrifuged at $800 \mathrm{~g}$ for 10 minutes within $24 \mathrm{~h}$ of sampling. The CellSearch® System (Veridex LLC, Co., Ltd) was used to measure the CECs, CD34+CECs, and CTCs. The CellSearch ${ }^{\circledR}$ System consists of CellSave Preservative Tubes, the CellTracks ${ }^{\circledR}$ Autoprep ${ }^{\circledR}$ System (a fully automated sample preparation system), the CellSearch ${ }^{\circledR}$ Circulating Endothelial Cell Kit, the CellSearch® Circulating Tumor Cell Kit, and the CellTracks Analyzer II® (a semi-automated fluorescence microscope). The CECs were identified as 4,6-diamino-2-phenylindole (DAPI)+, CD45-, CD146+, and CD105+ cells. CECs were additionally stained with anti-CD34 antibody (Clone AC136; Miltenyi Biotec, Germany), and CD34 expression was evaluated on an extra channel of the CellSearch system. Therefore, the CD34+ CECs were identified as DAPI+, CD45-, CD146+, CD105+, and CD34+ cells. The CTCs were defined as DAPI+CD45-EpCAM+CK8+CK18+CK19+ cells. All evaluations were performed by the same operator.

For enzyme-linked immunosorbent assay (ELISA) and 5FU and GBL measurements, 15-mL aliquots of heparinized peripheral venous blood were collected on days 1, 15, 43, and 57, kept at room temperature for less than 30 minutes, and centrifuged at 3000 r.p.m. at $4{ }^{\circ} \mathrm{C}$ for 15 minutes. Plasma 
samples were stored at $-80^{\circ} \mathrm{C}$ until measurements of 5FU, GBL, and by ELISA. The plasma levels of

GBL and 5FU were determined by a gas chromatographic-mass spectrometric method (FALCO

Biosystems Ltd., Kyoto, Japan) ${ }^{23}$. Plasma levels of VEGF (Quantikine ${ }^{\circledR}$, Human VEGF Immunoassay;

R\&D Systems, Inc., Minneapolis, MN, USA), MCP-1 (Quantikine ${ }^{\circledR}$, Human MCP-1 Immunoassay;

R\&D Systems, Inc., Minneapolis, MN, USA), TSP-1 (Quantikine®, Human TSP-1 Immunoassay; R\&D

Systems, Inc., Minneapolis, MN, USA), M30 (M30® ELISA; PEVIVA AB, Bromma, Sweden), and M65

(M65® ELISA; PEVIVA AB, Bromma, Sweden) were measured by ELISA according to the manufacturer's instructions. M30 and M65 ELISAs detect different circulating forms of the protein cytokeratin $18{ }^{24,25}$. M30 recognizes a fragment of cytokeratin 18 cleaved during apoptosis while M65 recognizes both cleaved and uncleaved forms of cytokeratin $18^{26}$.

\section{Toxicity and clinical evaluations}

Toxicities were evaluated according to the National Cancer Institute Common Terminology

Criteria for Adverse Events (version 3.0) throughout the S-1 treatment. The clinical effect was assessed as progressive disease $(\mathrm{PD})$ or non-PD.

\section{Statistical analysis}

To evaluate differences in the distribution of the markers, statistical significance was assessed 
by the Wilcoxon signed-rank test. JMP version 9 software (SAS Institute Inc., Cary, NC, USA) was used for statistical analysis.

\section{Results}

\section{Patient characteristics and clinical course}

A total of 18 female patients with histologically-proven invasive breast carcinoma and metastatic or relapsed breast cancer were enrolled in this study. The patients' characteristics are described in Table 1. The clinical course and toxicities are described in Table 2. Endocrine therapy was administered concurrently to 15 patients (83.3\%). Six patients (33.3\%) aborted S-1 administration because of side effects or progressive disease before day 85 . Four patients (22.2\%) had progressive disease (PD) by day 85. Toxicities greater than or equal to grade 2 were anemia (16.7\%), leukopenia (16.7\%), neutropenia (16.7\%), rash (16.7\%), malaise (11.1\%), pigmentation (5.6\%), and diarrhea (5.6\%). Nine patients $(50 \%)$ had no toxicity greater than grade 2 .

\section{Blood levels of 5-FU and GBL}

Before the administration of S-1 on days 1 and 43 (before the $2^{\text {nd }}$ cycle of S-1 administration), 5-FU was not detected in the blood of any patients. The mean 5-FU concentrations are shown in Table 3.

The plasma GBL levels are shown in Fig. $1 \mathrm{~b}$ and Table 3. The individual plasma 5-FU and GBL levels 
significantly elevated at day 15 compared to day $1(P=0.008)$. The levels were also elevated on day 57 compared with those on day $1(P=0.008)$ and day $43(P=0.008)$. The plasma GBL level on day 43 was significantly decreased from that on day $15(P=0.016)$. Plasma GBL can be detected before S-1 administration because it exists endogenously in human plasma.

\section{Change in CECs and CD34 + CECs during S-1 treatment}

The mean CEC and CD34+ CEC counts had a tendency to decrease notably from day 1 to day

15 and were suppressed until day 85. The reductions in CEC counts were significant on day $29(P=0.010$ vs. day1) and day 85 ( $P=0.002$ vs. day 1 ) (Fig. 2a and Table 3). The reductions in CD34+ CEC counts were significant on day $29(P=0.017$ vs. day 1$)$ and day 85 ( $P=0.003$ vs. day 1$)$ (Fig. $2 \mathrm{~b}$ and Table 3 ).

\section{Angiogenesis-related proteins}

The mean VEGF level significantly decreased on day $15(P=0.012)$ (Fig. 2c). The plasma MCP-1 level significantly increased from day 1 to day $15(P=0.002)$ and from day 43 to day $57(P=$ $0.002)$, and there was a statistically significant decrease from day 15 to day $43(P=0.005)$. The mean TSP-1 level on day 57 significantly decreased from day $1(P=0.016)$ (Table 3$)$.

\section{Change in the CTCs, M30, and M65}


The mean CTC counts had a tendency to decrease from day 1 until day 29 and then increase from day 29 to day 85, although there was large individual variation. The mean CTC counts significantly increased on day 43 from day 29 level $(P=0.031)$. The mean levels of M30 and M65 tended to converge from day 1 until day 57 (Table 3). No statistical correlation was observed between clinical effects and any measured biomarkers except M30 change in value from day 1 to day 15 (Table 4). M30 of the patients with non-PD increased from day 1 to day 15, while that of the patients with PD decreased from day 1 to day $15(P=0.030)$.

\section{Discussion}

We showed that CEC counts after S-1 administration notably decreased on day 15 and were significantly suppressed until day 85 in MBC patients. The plasma levels of 5FU and GBL significantly increased after S-1 administration. The plasma VEGF levels significantly decreased from day 1 to day 15 .

One of the limitations of this study was that blood samples obtained for analysis were taken $1 \mathrm{~h}$ after S-1 administration although the level of $5 \mathrm{FU}$ at $1 \mathrm{~h}$ after administration cannot be used as a representative level of systemic exposure. Endogenous GBL is observed in not only cancer patients but also healthy volunteers without administration of S-1, and no differences in the endogenous concentration of GBL were found between them ${ }^{27}$. Currently, the plasma pharmacokinetics of GBL after S-1 administration are unknown, although Emi et al. showed that the values of Tmax for GBL after UFT 
administration were $1.2+/-0.6 \mathrm{~h}^{27}$. Sampling for other biomarkers, including CEC counts or VEGF, are also considered to be appropriate $1 \mathrm{~h}$ after S-1 administration. On the basis of these factors together with a feasible schedule in an outpatient setting, we decided to collect blood $1 \mathrm{~h}$ after S-1 administration.

Of 18 patients, 15 (83.3\%) had combined treatments with hormone therapy or zoledronic acid, and 12 patients (72.2\%) secured S-1 administration without unacceptable toxicity or PD. Considering that 14 patients $(77.8 \%)$ had non-PD, S-1 is suitable for MBC patients. No statistical correlation between clinical effects and any measured biomarkers except M30 change in value from day 1 to day 15 was observed. As reported before ${ }^{28,29}$, M30 can be used to assess tumor apoptosis. However, the number of patients was small because the primary endpoint of this study was to explore corresponding levels of CECs and the change in angiogenesis-related factors. Additionally, 3 out of 4 patients with PD discontinued S-1 before day 85 . These results are preliminary, and the correlation between clinical effects and biomarkers remains to be elucidated in the future.

VEGF is a potent angiogenic factor that is known to promote the mobilization of bone marrow-derived CEPs, which subsequently differentiate into mature $\mathrm{CECs}{ }^{30}$. A previous study of in vitro tube formation assay showed that GBL suppressed VEGF-mediated angiogenesis and that the $\mathrm{IC}_{50}$ of the anti-angiogenic effect was $25.8 \mathrm{ng} / \mathrm{mL}^{11}$. Nagai et al. also reported that UFT and its metabolite GBL inhibited angiogenesis induced by VEGF in cervical cancer ${ }^{18}$. In our present study, the mean GBL levels were $41.3 \pm 15.8$ and $41.0 \pm 11.2 \mathrm{mg} / \mathrm{mL}$ at $1 \mathrm{~h}$ after $\mathrm{S}-1$ administration on days 15 and 57 , respectively, 
which exceeded the $\mathrm{IC}_{50}$ of the anti-angiogenic effect ${ }^{11}$. From this result and that VEGF levels significantly decreased from day 1 to day 15 , CEPs appear to be suppressed via VEGF inhibition during S-1 administration in the same manner as caused by UFT.

Thus, S-1 should have not only a well-known cytotoxic effect but also an anti-angiogenic effect. More effective strategies may be developed for treatment of MBC; for example, S-1 is supposed to be more effective for tumors with abundant neovascularization. Approved angiogenesis inhibitors are suggested to have a strong angiogenic effect soon after discontinuation. When a patient needs to discontinue an angiogenesis inhibitor because of side effects, S-1 may have the potential to inhibit this reinduction. S-1 demonstrates marked benefits to MBC patients, considering approved anti-angiogenic drugs that are recommended for use with chemotherapeutic agents. Regarding the surrogate marker, the reduced CEC counts on day 15 suggest that the anti-angiogenic effect continues until day 85 .

CECs are composed of two distinct populations: vascular-derived CECs and bone marrow-derived CEPs. The former is considered to be mature CECs and caused by the damaged endothelium of the vasculature and the latter is regarded to be CEPs that contribute to neovascularization. Both have an important role in neovascularization and tumor growth, but there is no standard way to evaluate CEC counts and distinguish between them at present ${ }^{31}$. We used the CellSearch ${ }^{\circledR}$ System to detect CECs, because of the automated nature of the CellTracks Analyzer II ${ }^{\circ}$, which reduces measurement deviations between different institutes. Although CD34 is expressed in not only endothelial 
progenitor cells but also in some mature endothelial cells, it has been widely used to identify progenitor cells with clonogenic potential ${ }^{19}$. We used CD34-positive CECs as populations similar to CEPs.

In summary, plasma GBL levels were significantly elevated, and CEC counts were suppressed possibly via VEGF inhibition during S-1 administration. S-1 appeared to have anti-angiogenic activity, but the correlation between clinical effect and biomarkers including CEC counts was not observed in this exploratory study. Further studies are warranted to investigate the association between CEC dynamism and clinical outcomes in other situations, such as neoadjuvant or adjuvant settings.

\section{Conflict of Interest Statement}

Wakako Tsuji was an employee of Kyoto University's Sponsored Research Program funded by Taiho Pharmaceutical Co. Ltd. Masakazu Toi and Hiroshi Ishiguro received an honoraria and a research funding from Taiho Pharmaceutical Co. Ltd. No potential conflicts of interest were disclosed by the other authors.

\section{Acknowledgments}

We express our gratitude to the patients who participated in this exploratory trial. We thank Dr.

Yasufumi Teramura (Hikone Municipal Hospital, Shiga), Dr. Satoru Nishimura, and Dr. Yasuo Matsutani

(Tenri Hospital, Nara) for providing data support. We also thank Ms. Masako Ishida for her excellent clinical research assistance. We appreciate Dr. Teiji Takechi (Taiho Pharmaceutical Co. Ltd., Tokyo) for 
his critical review of the manuscript. This study was supported by Taiho Pharmaceutical Co. Ltd.

\section{Figure legends}

Fig. 1a: Scheme of S-1 administration and blood collection. The patients received S-1 for 28 days followed by a 14-day rest in one cycle.

Fig. 1b: Plasma GBL levels on days 1, 15, 43, and 57. The plasma GBL levels significantly increased on the $14^{\text {th }}$ day from the first day in each cycle. Data are shown as mean \pm SD. $* P<0.05$.

Fig. 2: Changes in CEC (a) and CD34+ CEC (b) counts from day1 through day85. Changes in plasma VEGF levels from day 1 to day 57 (c). Data are shown as mean \pm SD. $* P<0.05$.

Table 1: Baseline characteristics of the patients $(n=18)$.

Table 2: Clinical evaluations and toxicities of the patients $(\mathrm{n}=18)$

Table 3: Plasma biomarker levels from day 1 through day 85 . Measurement values are shown as mean \pm SD. $* P<0.05$. 
Table 4: Biomarker changes in value from day 1 to day 15 by the patients with non-PD and PD. Values are indicated as mean $\pm \mathrm{SD} . * P<0.05$.

\section{References}

1. Bertolini F, Paul S, Mancuso P, et al: Maximum tolerable dose and low-dose metronomic chemotherapy have opposite effects on the mobilization and viability of circulating endothelial progenitor cells. Cancer Res 63:4342-6, 2003

2. Fujii S, Ikenaka K, Fukushima M, et al: Effect of uracil and its derivatives on antitumor activity of 5-fluorouracil and 1-(2-tetrahydrofuryl)-5-fluorouracil. Gann 69:763-72, 1978

3. Milano G, Ferrero JM, Francois E: Comparative pharmacology of oral fluoropyrimidines: a focus on pharmacokinetics, pharmacodynamics and pharmacomodulation. Br J Cancer 91:613-7, 2004

4. Watanabe T, Sano M, Takashima S, et al: Oral uracil and tegafur compared with classic cyclophosphamide, methotrexate, fluorouracil as postoperative chemotherapy in patients with node-negative, high-risk breast cancer: National Surgical Adjuvant Study for Breast Cancer 01 Trial. J Clin Oncol 27:1368-74, 2009

5. $\quad$ Ohashi Y, Watanabe T, Sano M, et al: Efficacy of oral tegafur-uracil (UFT) as adjuvant therapy as compared with classical cyclophosphamide, methotrexate, and 5-fluorouracil (CMF) in early breast cancer: a pooled analysis of two randomized controlled trials (N.SAS-BC 01 trial and CUBC trial). Breast Cancer Res Treat 119:633-41, 2010

6. Gennari A, Sormani MP, Pronzato P, et al: HER2 status and efficacy of adjuvant anthracyclines in early breast cancer: a pooled analysis of randomized trials. J Natl Cancer Inst 100:14-20, 2008

7. Hayes DF, Thor AD, Dressler LG, et al: HER2 and response to paclitaxel in node-positive breast cancer. N Engl J Med 357:1496-506, 2007

8. Kerbel RS, Kamen BA: The anti-angiogenic basis of metronomic chemotherapy. Nat Rev Cancer 4:423-36, 2004

9. Munoz R, Man S, Shaked Y, et al: Highly efficacious nontoxic preclinical treatment for advanced metastatic breast cancer using combination oral 
UFT-cyclophosphamide metronomic chemotherapy. Cancer Res 66:3386-91, 2006

10. Browder T, Butterfield CE, Kraling BM, et al: Antiangiogenic scheduling of chemotherapy improves efficacy against experimental drug-resistant cancer. Cancer Res 60:1878-86, 2000

11. Basaki Y, Chikahisa L, Aoyagi K, et al: gamma-Hydroxybutyric acid and 5 -fluorouracil, metabolites of UFT, inhibit the angiogenesis induced by vascular endothelial growth factor. Angiogenesis 4:163-73, 2001

12. Yonekura K, Basaki Y, Chikahisa L, et al: UFT and its metabolites inhibit the angiogenesis induced by murine renal cell carcinoma, as determined by a dorsal air sac assay in mice. Clin Cancer Res 5:2185-91, 1999

13. Asahara T, Murohara T, Sullivan A, et al: Isolation of putative progenitor endothelial cells for angiogenesis. Science 275:964-7, 1997

14. Bertolini F, Mancuso P, Shaked Y, et al: Molecular and cellular biomarkers for angiogenesis in clinical oncology. Drug Discov Today 12:806-12, 2007

15. Furstenberger G, von Moos R, Lucas R, et al: Circulating endothelial cells and angiogenic serum factors during neoadjuvant chemotherapy of primary breast cancer. Br J Cancer 94:524-31, 2006

16. Naik RP, Jin D, Chuang E, et al: Circulating endothelial progenitor cells correlate to stage in patients with invasive breast cancer. Breast Cancer Res Treat 107:133-8, 2008

17. Shaked Y, Emmenegger U, Man S, et al: Optimal biologic dose of metronomic chemotherapy regimens is associated with maximum antiangiogenic activity. Blood 106:3058-61, 2005

18. Nagai N, Mukai K, Hirata E, et al: UFT and its metabolite gamma-butyrolactone (GBL) inhibit angiogenesis induced by vascular endothelial growth factor in advanced cervical carcinoma. Med Oncol 25:214-21, 2008

19. Bertolini F, Shaked Y, Mancuso P, et al: The multifaceted circulating endothelial cell in cancer: towards marker and target identification. Nat Rev Cancer 6:835-45, 2006

20. Mancuso P, Colleoni M, Calleri A, et al: Circulating endothelial-cell kinetics and viability predict survival in breast cancer patients receiving metronomic chemotherapy. Blood 108:452-9, 2006

21. Allegrini G, Falcone A, Fioravanti A, et al: A pharmacokinetic and pharmacodynamic study on metronomic irinotecan in metastatic colorectal cancer patients. Br J Cancer 98:1312-9, 2008

22. Ueno T, Toi M, Saji H, et al: Significance of macrophage chemoattractant 
protein-1 in macrophage recruitment, angiogenesis, and survival in human breast cancer. Clin Cancer Res 6:3282-9, 2000

23. Fukui Y, Matsusima E, Muramoto K, et al: Validation of a simple gas chromatographic-mass spectrometric method for the determination of gamma-butyrolactone in human plasma. J Chromatogr B Analyt Technol Biomed Life Sci 785:73-80, 2003

24. Cristofanilli M, Budd GT, Ellis MJ, et al: Circulating tumor cells, disease progression, and survival in metastatic breast cancer. N Engl J Med 351:781-91, 2004

25. Cummings J, Ward TH, Greystoke A, et al: Biomarker method validation in anticancer drug development. Br J Pharmacol 153:646-56, 2008

26. Olofsson MH, Ueno T, Pan Y, et al: Cytokeratin-18 is a useful serum biomarker for early determination of response of breast carcinomas to chemotherapy. Clinical cancer research : an official journal of the American Association for Cancer Research 13:3198-206, 2007

27. Emi Y, Sumiyoshi Y, Oki E, et al: Pharmacokinetics of gamma-hydroxybutylic acid (GHB) and gamma-butyrolactone (GBL), the anti-angiogenic metabolites of oral fluoropyrimidine UFT, in patients with gastric cancer. Fukuoka Igaku Zasshi 98:418-24, 2007

28. Kramer G, Schwarz S, Hagg M, et al: Docetaxel induces apoptosis in hormone refractory prostate carcinomas during multiple treatment cycles. Br J Cancer 94:1592-8, 2006

29. Ulukaya E, Yilmaztepe A, Akgoz S, et al: The levels of caspase-cleaved cytokeratin 18 are elevated in serum from patients with lung cancer and helpful to predict the survival. Lung Cancer 56:399-404, 2007

30. Asahara T, Takahashi T, Masuda H, et al: VEGF contributes to postnatal neovascularization by mobilizing bone marrow-derived endothelial progenitor cells. EMBO J 18:3964-72, 1999

31. Ali AM, Ueno T, Tanaka S, et al: Determining circulating endothelial cells using CellSearch system during preoperative systemic chemotherapy in breast cancer patients. Eur J Cancer 47:2265-72, 2011 
a

$1^{\text {st }}$ cycle $2^{\text {nd }}$ cycle

\begin{tabular}{|c|c|c|c|c}
$\mathrm{S}-1$ & $\mathrm{~S}-1$ & & $\mathrm{~S}-1$ \\
\hline
\end{tabular}

$\begin{array}{lllllllllllll}\text { day } 1 & 8 & 15 & 22 & 29 & 36 & 43 & 50 & 57 & 64 & 71 & 78 & 85\end{array}$
CEC,
CTC
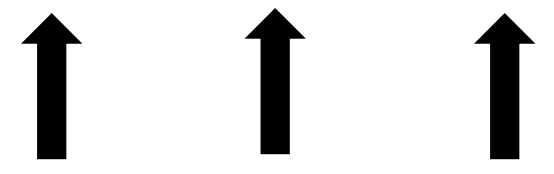

1

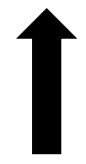

5FU, GBL,

VEGF,

MCP-1,
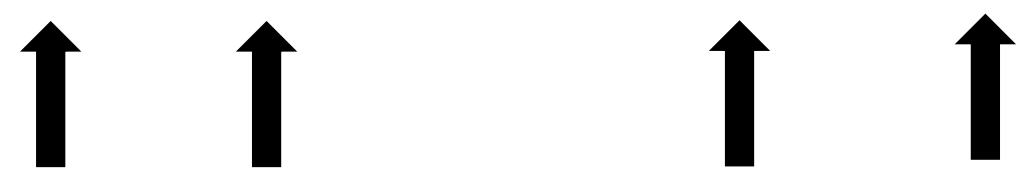

TSP-1,

M30,

M65

b

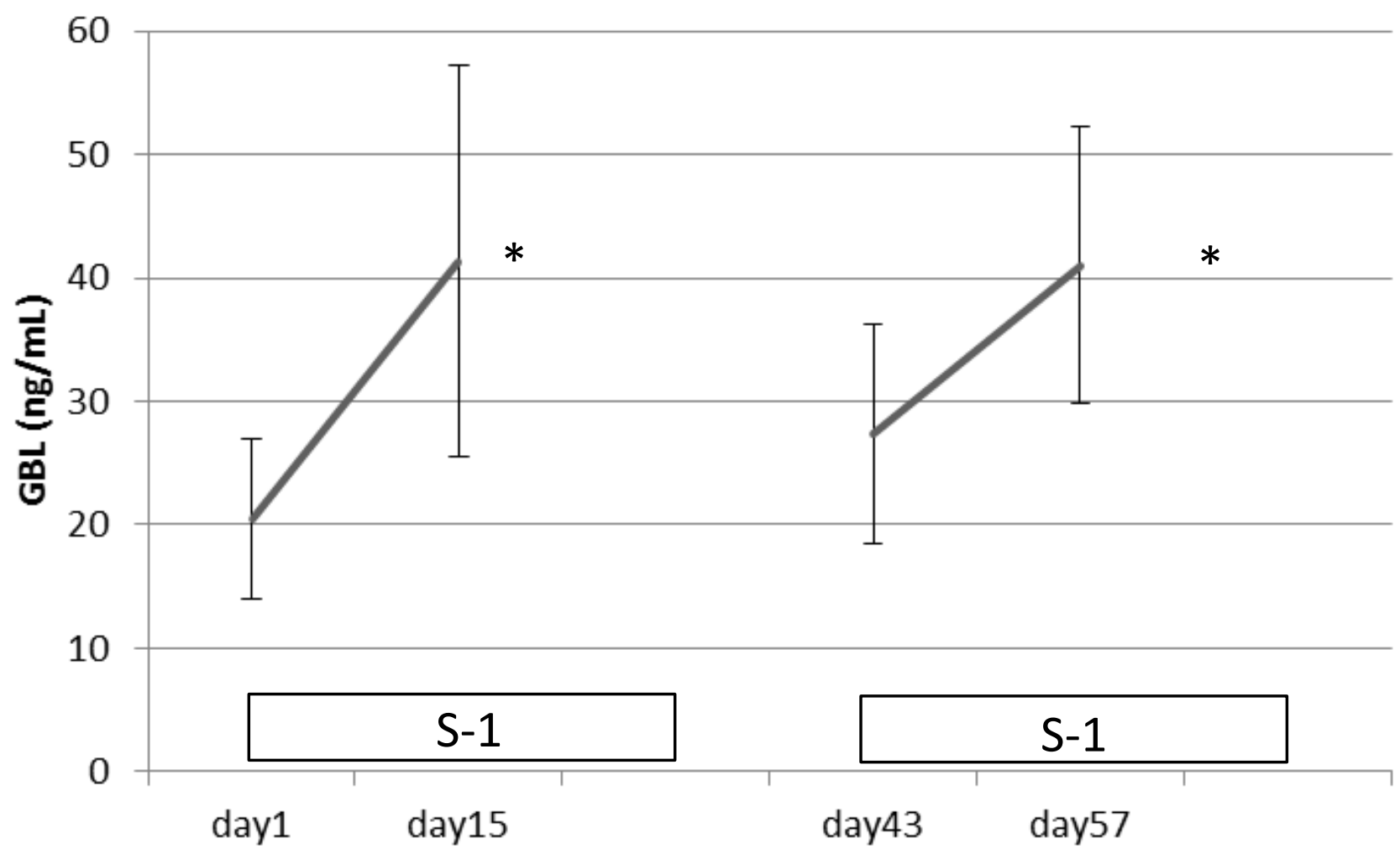


F 2 京都大学

a

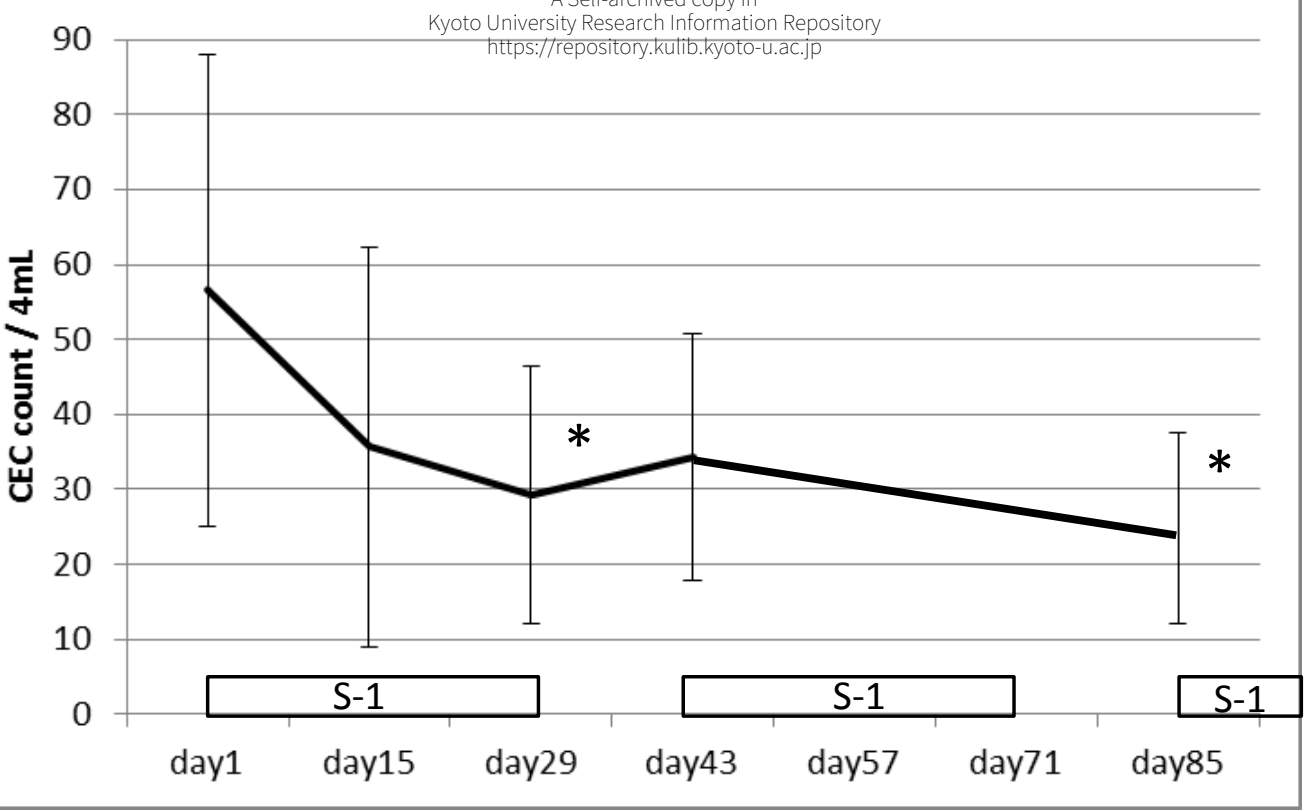

b

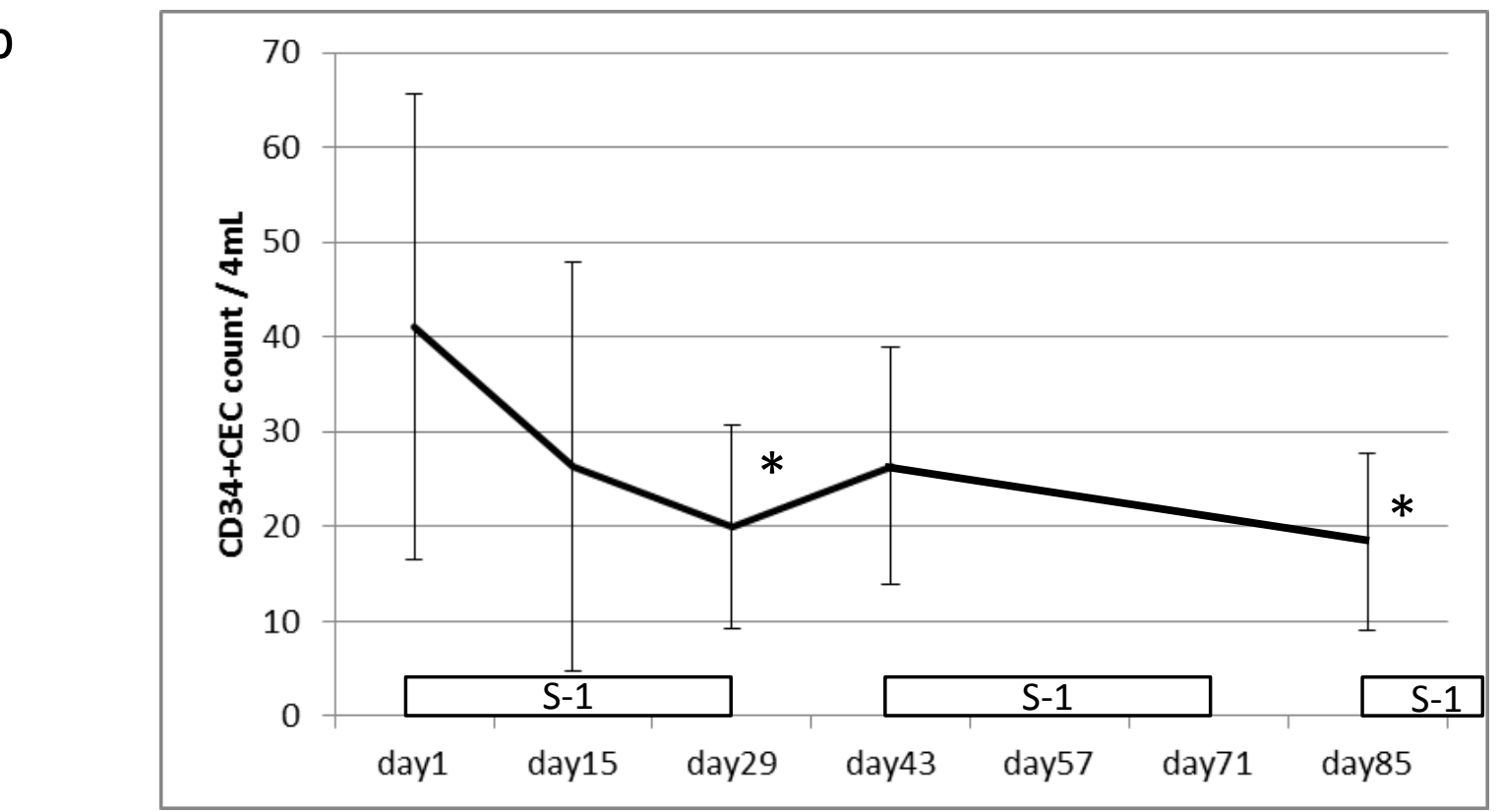

C

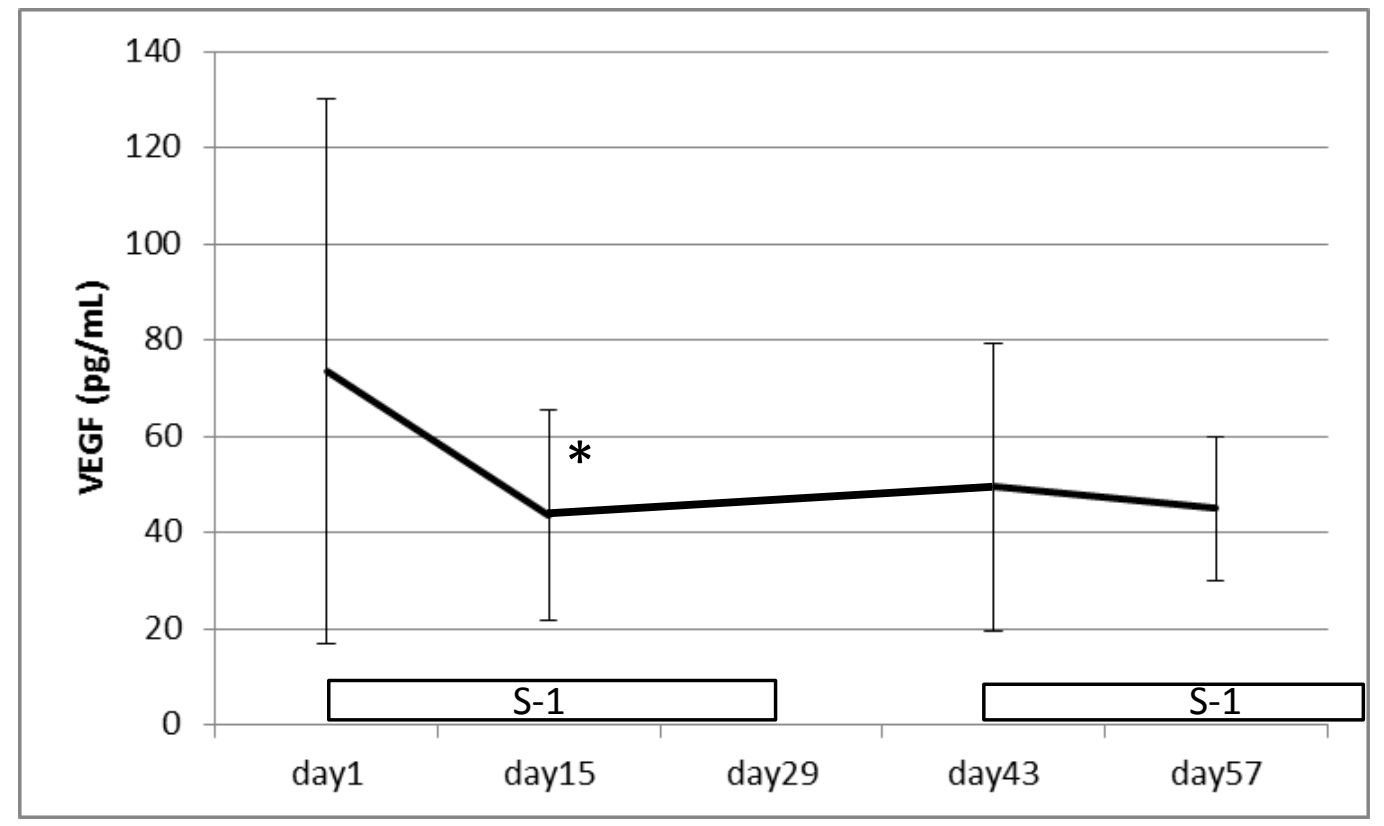

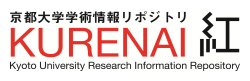




\section{Characteristic}

Number of enrolled

\section{Age, y}

Median

Range

Menopausal status

Premenopausal

Postmenopausal

Metastatic sites

Bone

Lung/Pleura

Lymph nodes

Liver

Breast (StagelV)

Brain

Pericardium

No. of metastatic sites
No. of patients $\%$

18

61

37-76 \begin{tabular}{|r|r|}
4 & $22.2 \%$ \\
\hline 14 & $77.8 \%$
\end{tabular}

$1266.7 \%$

9 $50.0 \%$

$844.4 \%$

$422.2 \%$

$3 \quad 16.7 \%$

$211.1 \%$

$15.6 \%$

$422.2 \%$

$950.0 \%$

$527.8 \%$

$16 \quad 88.9 \%$

$211.1 \%$

$15.6 \%$

$1161.1 \%$

$633.3 \%$

$15 \quad 83.3 \%$

$211.1 \%$

$15.6 \%$ 


\section{Table 2}

\begin{tabular}{|r|l|l|l|l|}
\hline $\begin{array}{l}\text { hormone } \\
\text { receptor } \\
\text { status }\end{array}$ & combined drug & $\begin{array}{l}\text { duration of } \\
\text { administration }\end{array}$ & $\begin{array}{l}\text { clinical } \\
\text { effect }\end{array}$ & toxicity (more than grade2) \\
\hline 1 positive & TAM+LHRH analog, ZA & day15 & non-PD & leukopenia (grade3), neutropenia (grade3), rash(grade2) \\
\hline 2 positive & LET, ZA & day85 & non-PD & leukopenia (grade3), neutropenia (grade2) \\
\hline 3 positive & EXE & day29 & non-PD & rush(grade2) \\
\hline 4 positive & LET, ZA & day85 & non-PD & leukopenia (grade2), neutropenia (grade2), anemia (grade2) \\
\hline 5 positive & EXE & day29 & PD & none \\
\hline 6 positive & EXE+LHRH analog & day85 & non-PD & none \\
\hline 7 positive & hd-TOR, ZA & day85 & non-PD & none \\
\hline 8 positive & hd-TOR & day29 & PD & malaise (grade2), pigmentation(grade2), rash (grade2) \\
\hline 9 positive & ZA & day85 & non-PD & anemia (grade2) \\
\hline 10 positive & LET+LHRH analog, ZA & day22 & non-PD & diarrhea (grade2) \\
\hline 11 positive & LET, ZA & day85 & non-PD & none \\
\hline 12 positive & LET & day85 & non-PD & none \\
\hline 13 positive & EXE & day85 & non-PD & none \\
\hline 14 negative & none & day85 & PD & anemia (grade2) \\
\hline 15 negative & none & day85 & non-PD & none \\
\hline 16 positive & ANA & day85 & PD & none \\
\hline 17 positive & none & day43 & non-PD & malaise (grade2) \\
\hline 18 positive & LET & day85 & non-PD & none \\
\hline
\end{tabular}




\section{Table 3}

\begin{tabular}{|c|c|c|c|c|c|c|c|c|c|c|c|}
\hline & day1 & day15 & & day29 & & day43 & & day57 & & day85 & \\
\hline & mean $\pm S D$ & mean $\pm S D$ & $\mathrm{P}$ & mean $\pm S D$ & $\mathrm{P}$ & mean \pm SD & $\mathrm{P}$ & mean $\pm S D$ & $\mathrm{P}$ & mean $\pm \mathrm{SD}$ & $\mathrm{P}$ \\
\hline $5 \mathrm{FU}(\mathrm{ng} / \mathrm{mL})$ & 0 & $71.9 \pm 48.1$ & $0.001^{*}$ vs. day 1 & & & & 01.000 vs. day 1 & $86.3 \pm 46.2$ & $0.001^{*}$ vs.day 1 & & \\
\hline $\mathrm{GBL}(\mathrm{ng} / \mathrm{mL})$ & $20.5 \pm 6.5$ & $41.3 \pm 15.8$ & $0.008^{*}$ vs. day 1 & & & $27.3 \pm 8.9$ & 0.109 vs. day 1 & $41.0 \pm 11.2$ & $0.008^{*}$ vs.day 1 & & \\
\hline CEC (cells $/ 4 \mathrm{~mL}$ ) & $56.5 \pm 31.5$ & $35.7 \pm 26.7$ & 0.082 vs. day 1 & $29.3 \pm 17.2$ & $0.010^{\star}$ vs. day 1 & $34.3 \pm 16.4$ & 0.064 vs. day 1 & & & $24.8 \pm 12.6$ & $0.002^{*}$ vs. day 1 \\
\hline CD34+ CEC (cells/4mL) & $41.1 \pm 24.6$ & $26.3 \pm 21.6$ & 0.151 vs. day 1 & $19.9 \pm 10.7$ & $0.017^{\star}$ vs. day 1 & $26.4 \pm 12.5$ & 0.129 vs. day 1 & & & $18.3 \pm 9.3$ & $0.003^{*}$ vs. day 1 \\
\hline VEGF (pg/mL) & $73.6 \pm 56.5$ & $43.8 \pm 21.9$ & $0.012^{*}$ vs. day 1 & & & $47.3 \pm 29.6$ & 0.129 vs. day 1 & $39.7 \pm 15.3$ & 0.424 vs.day 1 & & \\
\hline MCP-1 (pg/mL) & $202.7 \pm 64.6$ & $276.1 \pm 107.5$ & $0.002^{*}$ vs. day 1 & & & $175.1 \pm 46.5$ & 0.898 vs. day 1 & $232.6 \pm 64.0$ & 0.206 vs. day 1 & & \\
\hline TSP-1 (ng/mL) & $1.49 \pm 0.74$ & $1.01 \pm 0.41$ & 0.129 vs. day 1 & & & $1.09 \pm 0.62$ & 0.064 vs. day 1 & $1.06 \pm 0.48$ & $0.016^{\star}$ vs. day 1 & & \\
\hline CTC (cells/7.5mL) & $13.3 \pm 35.1$ & $3.0 \pm 3.8$ & 0.681 vs. day 1 & $1.5 \pm 2.4$ & 0.313 vs. day 1 & $4.2 \pm 7.7$ & 1.000 vs. day 1 & & & $5.7 \pm 14.2$ & 0.914 vs. day 1 \\
\hline $\mathrm{M} 30(\mathrm{U} / \mathrm{L})$ & $170.3 \pm 63.3$ & $153.6 \pm 54.9$ & 0.970 vs. day 1 & & & $140.5 \pm 41.9$ & 0.569 vs. day 1 & $136.2 \pm 32.6$ & 0.733 vs. day 1 & & \\
\hline M65 (U/L) & $626.7 \pm 374.2$ & $455.2 \pm 264.7$ & 0.233 vs. day 1 & & & $426.4 \pm 161.8$ & 0.233 vs. day 1 & $413.7 \pm 174.2$ & 0.077 vs. day 1 & & \\
\hline
\end{tabular}




\section{Table 4}

\begin{tabular}{|c|c|c|c|}
\hline & \multicolumn{2}{|c|}{ Change in value from day 1 to day 15} & \\
\hline & Patients with non-PD & Patients with PD & \\
\hline & mean $\pm S D$ & mean \pm SD & $P$ \\
\hline $5 F U(n g / m L)$ & $71.9 \pm 52.8$ & $55.7 \pm 40.2$ & 0.856 \\
\hline $\mathrm{GBL}(\mathrm{ng} / \mathrm{mL})$ & $21.8 \pm 13.7$ & $20.9 \pm 11.3$ & 0.893 \\
\hline CEC (cells/4mL) & $-19.3 \pm 33.9$ & $-38.0 \pm 28.7$ & 0.281 \\
\hline CD34+ CEC (cells/4mL) & $-17.9 \pm 27.7$ & $-14.0 \pm 17.5$ & 1.000 \\
\hline $\operatorname{VEGF}(\mathrm{pg} / \mathrm{mL})$ & $-21.9 \pm 37.3$ & $-57.6 \pm 54.4$ & 0.152 \\
\hline MCP-1 $(\mathrm{pg} / \mathrm{mL})$ & $56.5 \pm 43.7$ & $132.9 \pm 160.7$ & 0.339 \\
\hline TSP-1 (ng/mL) & $-0.398 \pm 0.614$ & $-0.285 \pm 0.784$ & 0.710 \\
\hline CTC (cells $/ 7.5 \mathrm{~mL}$ ) & $-1.3 \pm 6.2$ & $-1.0 \pm 5.4$ & 0.646 \\
\hline M30 (U/L) & $33.3 \pm 36.2$ & $-24.5 \pm 62.4$ & $0.030^{*}$ \\
\hline M65 (U/L) & $-216.7 \pm 306.9$ & $-13.72 \pm 113.5$ & 0.265 \\
\hline
\end{tabular}

